\title{
AVALIAÇÃO DE PROGRAMAS DE ILUMINAÇÃO SOBRE O DESEMPENHO ZOOTÉCNICO DE POEDEIRAS LEVES
}

\author{
Evaluation of lightning programs upon the performance of white egg layers
}

\author{
Henrique Jorge de Freitas ${ }^{1}$, Judas Tadeu de Barros Cotta ${ }^{2}$, Antonio Ilson Gomes de Oliveira ${ }^{3}$, \\ Clóvis Eliseu Gewher ${ }^{4}$
}

\begin{abstract}
RESUMO
Foi avaliado o efeito de programas de iluminação sobre o desempenho zootécnico de poedeiras leves ao final de produção, em experimento realizado no Departamento de Zootecnia da Universidade Federal de Lavras - UFLA. Foram testados um programa de iluminação intermitente e outro com apenas iluminação natural, em dias de luminosidade crescente, em comparação com um programa contínuo com a utilização de 288 poedeiras leves da linhagem Leghorn branca. As aves foram alojadas em galpão dividido em 3 ambientes, por lona de plástico preta, de forma que a iluminação de um não interferisse na dos outros. Cada ambiente experimental apresentou 32 gaiolas nas quais foram alojadas 96 galinhas. Foi realizado um período pré-experimental de 28 dias. O período experimental teve duração de 112 dias, em que avaliou-se o consumo de ração, a produção de ovos, o peso e a massa dos ovos e a conversão alimentar por massa de ovos. O delineamento utilizado foi o inteiramente ao acaso, com restrição nos tratamentos, e oito repetições. As aves submetidas ao programa de iluminação intermitente e iluminação natural consumiram $(\mathrm{P}<0,05)$ menor quantidade de ração em comparação com as do programa contínuo. O peso dos ovos foi semelhante $(\mathrm{P}>0,05)$ nos programas de iluminação testados. A produção e a massa de ovos foi maior $(\mathrm{P}<0,05)$ no programa luz natural. As aves do programa luz natural apresentaram melhor $(\mathrm{P}<0,05)$ conversão alimentar quando comparadas com as do intermitente, enquanto as do programa contínuo apresentaram pior conversão. Pode-se concluir que o programa de iluminação intermitente ou apenas iluminação natural, em dias de luminosidade crescente, pode ser usado em galpões abertos permitindo manter o desempenho zootécnico de poedeiras leves, ao final de postura.
\end{abstract}

Termos para indexação: Dia Subjetivo, Iluminação Fracionada, Programa de Luz, Iluminação Natural.

\section{ABSTRACT}

This experiment was conducted with objective to evaluate the effect of lighting programs for light at the Department of Animal Science of the Federal University of Lavras. An intermittent lighting program and another with only natural lighting on days of increasing lighting as compared with a continuous program by utilizing 288 light layers were tested. The hens were keept in a house divided into three environments in such a way the lighting of one did not interfere with that of the other one. The experimental period lasted 112 days, divided into four periods of 28 days. The design utilized was the completely randomized with restriction in the treatments and eight replicates. The means of the treatments were compared with the SNK test (5\%). The hens of the continuous lighting program presented greater feed intake $(\mathrm{P}<0.05)$ and worse feed conversion whereas those of the natural light program, greater egg yield. The hens in the intermittent lighting program showed better viability $(\mathrm{P}<0.05)$. In conclusion the intermittent lighting programs and only natural lighting on days of increasing lighting for light layers in the late production should be used in open houses in order to increase the hens production.

Index terms: subjective day, split lighting, light program, layers White Leghorn, intermittent lighting.

(Recebido para publicação em 13 de Janeiro de 2004 e aprovado em 21 de fevereiro de 2005)

\section{INTRODUÇÃO}

No Brasil, a criação intensiva de aves é realizada em galpões abertos para aproveitar os recursos ambientais existentes. Os galpões de criação são equipados para otimizar o desempenho zootécnico da produção. A modernização tecnológica ocorrida nas últimas décadas não levou em consideração a limitação quanto ao uso de energia elétrica.
O racionamento de energia elétrica realizado em 2001 ocorreu em razão de vários fatores. Medidas de emergência foram aplicadas, para diminuir o consumo, bem como aumentar a geração e distribuição (CEMIG, 2001) e por isso, os diversos setores produtivos da economia tiveram de se ajustar à nova realidade.

Para integrar o setor avícola a esta realidade, diversos estudos são necessários. A substituição de lâmpadas incandescentes por outras de vapor de sódio traria

\footnotetext{
1. Professor do Departamento de Ciências Agrárias da Universidade Federal do Acre - Doutorando em Produção Animal - Universidade Federal de Lavras/UFLA - Caixa Postal 3037 - 37.200-000 - Lavras, MG - henriqufac@bol.com.br

2. Professor Adjunto do Departamento de Zootecnia/UFLA - jtbcotta@ufla.br

3. Professor Titular Aposentado/UFLA - ailson@ufla.br

4. Zootecnista, MSc.- Doutorando em Produção Animal/UFLA - cloviseg@bol.com.br
} 
uma economia de cerca de $70 \%$ de energia elétrica. Outros procedimentos causariam uma redução ainda mais significativa (COTTA, 2002).

Em aves de postura é conhecida a função da luz elétrica nos programas de iluminação, aumentando o fotoperíodo e estimulando a produção de ovos. No entanto, no Brasil este tema tem sido pouco estudado, pois, com o uso de galpões abertos, o tempo de iluminação artificial diária é muito menor, quando comparado com países em que se trabalha com galpões fechados.

Nos países onde as instalações são fechadas, têm sido desenvolvidas pesquisas com programas de luz intermitente, com a finalidade de reduzir o período de iluminação artificial diário, sem que os índices zootécnicos e a concentração de postura sejam afetados (SAUVEUR, 1996).

O programa de iluminação ideal seria aquele que proporcionasse a máxima produção com o mínimo consumo de ração e gasto de energia elétrica.

Estudos sobre programas de iluminação para aves de postura vêm sendo preconizados há várias décadas por diversos autores, que relatam a influência dos programas de iluminação sobre a fase de crescimento e maturidade sexual em galinhas poedeiras.

Engster citado por Ernst et al. (1984) avaliou um sistema para economizar energia elétrica em galpão aberto, fornecendo somente 15 minutos de luz artificial (LA) por dia, em um programa de 8hE:15minLA:2h45minE:13h Luz Natural. Os testes foram realizados com aves de 36 semanas de idade. Observou-se diminuição do consumo de ração e redução na produção de ovos. Esse programa foi considerado interessante por Rowland (1987), pois reduziu em $75 \%$ o gasto de energia elétrica nos galpões e melhorou a eficiência alimentar das aves. Entretanto, foi observada uma diminuição de 0,5 a $1 \%$ na postura de ovos.

O uso da iluminação artificial em aves reprodutoras e de postura comercial é uma das mais poderosas ferramentas de manejo disponíveis para o produtor avícola. O início da postura pode ser antecipado ou retardado; a taxa de postura pode ser influenciada e seu intervalo alterado; a qualidade da casca pode ser melhorada; o tamanho do ovo pode ser otimizado e a eficiência alimentar pode ser maximizada pelo fornecimento apropriado de um regime luminoso (ETCHES, 1996).

Realizou-se este trabalho com o objetivo de verificar o efeito do uso de iluminação natural e de um programa de iluminação intermitente sobre o desempenho zootécnico de poedeiras leves, ao final de postura.

\section{MATERIAL E MÉTODOS}

O trabalho foi desenvolvido no Setor de Avicultura do Departamento de Zootecnia da Universidade Federal de Lavras - MG, e teve duração de 112 dias, dividido em quatro períodos de 28 dias.

O experimento foi realizado em galpão aberto medindo 16 x 8m, possuindo 96 gaiolas com comedouros tipo calha e bebedouros tipo "nipple". O galpão foi dividido em três ambientes, por lona de plástico preta, de forma a evitar a passagem de luz de um ambiente para os outros. Cada ambiente contou com 32 gaiolas. Foram utilizadas 288 poedeiras leves da linhagem Leghorn branca, no final do $1^{\circ}$ ciclo de produção.

Cada gaiola alojou três poedeiras. Foi realizado um período pré-experimental de 28 dias e no início do período experimental as aves apresentavam 51 semanas de idade.

A ração fornecida, a base de milho e farelo de soja, apresentava 15,8\% de Proteína Bruta (PB) e 2750 kcal de Energia Metabolizavel (EM) por kg.

O galpão foi iluminado por lâmpadas incandescentes de $40 \mathrm{w}$ e a intensidade luminosa medida, com luxímetro, com a finalidade de observar se a luminosidade de um ambiente estava influenciando os outros. No ambiente com programa de iluminação contínuo foi instalado "timer", com o objetivo de acender e apagar as luzes nos horários determinados; no tratamento com programa intermitente, acoplado ao "timer", foi instalado um temporizador que possibilitou desligar as luzes 15 segundos após terem sido acesas.

Os tratamentos foram:

Programa Contínuo - iluminação contínua com 15horas (natural + artificial) de fotoperíodo -as lâmpadas foram acesas às 4horas e apagadas ao amanhecer; acesas novamente às 18 horas, horário em que já estava escuro, e apagadas às 19horas.

Programa Intermitente - iluminação intermitente de 15horas (natural + artificial) - foram dados dois flashes de luz, sendo as lâmpadas acesas às 4horas e apagadas 15 seg após; novamente acesas às $18 \mathrm{~h} 59 \mathrm{~min} 45 \mathrm{seg}$ e apagadas às 19horas. Neste programa utilizou-se a noção do dia subjetivo, conforme descreve Sauveur (1996).

Programa Luz Natural - somente foi fornecida iluminação natural em dias de luminosidade crescente. O amanhecer e anoitecer do dia, para a região Sudeste, estão de acordo com Cotta (2002).

O consumo de ração foi registrado a cada período de 28 dias e, ao final do experimento expresso em gramas por ave por dia. Os ovos foram coletados duas vezes ao dia e a produção expressa em porcentagem por ave. Nos dois últimos dias de cada período, os dois primeiros 
ovos íntegros de cada parcela experimental foram coletados, identificados e pesados em balança digital com precisão de $0,01 \mathrm{~g}$. A massa de ovos foi calculada multiplicando-se o percentual de postura pelo peso dos ovos e expressa em gramas. A conversão alimentar por massa de ovos foi obtida mediante a divisão do consumo de ração (g) pela massa de ovos (g).

O delineamento utilizado foi o inteiramente casualizado, com restrição nos tratamentos (a iluminação de um tratamento não influenciou a dos outros) com oito repetições, e para a análise dos dados foi utilizado o programa SISVAR, descrito por Ferreira (2000).

\section{RESULTADOS E DISCUSSÃO}

O consumo de ração e a produção de ovos foram $(\mathrm{P}<0,05)$ influenciados pelos programas de iluminação (Tabela 1). As aves submetidas ao programa intermitente e ao de luz natural apresentaram menor consumo de ração no período experimental em comparação com as aves do programa contínuo. Com relação a produção de ovos, as aves do programa luz natural apresentaram maior produção de ovos, enquanto nas aves do contínuo esta foi semelhante à das aves do intermitente.

Em pesquisa realizada por Koelkebeck (1986), em revisão de Rowland (1987) e um em trabalho publicado por Morris et al. (1990), sobre a utilização de iluminação intermitente, concluí-se que, com este tipo de programa de luz, há redução de 0,5 a 1\% no consumo de ração quando comparado com programas de iluminação contínuos.

Midgley et al. (1988), criando galinhas das 37 às 72 semanas de idade afirmam que o consumo de ração foi reduzido em $5 \%$, quando do uso de programa de luz intermitente.

Etches (1996) afirma que o efeito da iluminação sobre a consumo de alimento está em função da atividade locomotora da ave, que fica reduzida ao mínimo, nos períodos escuros. Com a diminuição dos movimentos, o gasto de energia é também reduzido fazendo com que melhore a eficiência alimentar e diminua o consumo de ração nos programas de iluminação intermitente, o que está de acordo com o observado no presente trabalho, no qual também foi observada uma redução de $1,6 \%$ no consumo alimentar das aves submetidas ao programa intermitente quando comparadas as do programa contínuo.

Charles \& Tucker (1993) Lewis \& Perry (1990) e Midgley et al. (1988), em trabalhos de pesquisa, e Sauveur (1996), em revisão sobre fotoperiodismo e reprodução nas aves domésticas, afirmam que o fracionamento da duração do dia com a manutenção de uma noite de 8 horas permite manter a produtividade das aves, o que também foi constatado neste experimento.

A manutenção da produção de ovos aliada a qualidade dos ovos observada neste estudo, podem ser justificadas pelos experimentos realizados por Charles \& Tucker (1993) que, trabalhando com híbridos de postura, afirmam que estas aves são tão apuradas geneticamente para produção que se apresentam quase refratárias às mudanças de regime luminoso.

$\mathrm{O}$ peso dos ovos não foi influenciado $(\mathrm{P}>0,05)$ pelos programas de iluminação. Peso semelhante foi registrado nos ovos das aves que receberam iluminação contínua, intermitente e somente iluminação natural (Tabela 1).

Morris (1988), Sauveur \& Mongin (1983) e Nys \& Mongin (1981), afirmam que o peso dos ovos aumenta com a diminuição do ciclo luminoso, o que não foi observado neste experimento.

O resultado do presente estudo está de acordo com os encontrados por Charles \& Tucker (1993), Koelkebeck (1986) e Lewis \& Perry (1990) que afirmam não haver diferença entre o peso dos ovos de aves que se encontram sob fotoperíodo contínuo quando comparadas com o das que estão sob fotoperíodo intermitente. Segundo Etches (1996), o peso do ovo pode ser influenciado por vários fatores como a qualidade da ração, genética, peso e idade da galinha, assim como pelo programa de iluminação fornecido. Neste estudo a única fonte de variação foi o programa de iluminação e este não influenciou o peso dos ovos.

A massa dos ovos foi influenciada $(\mathrm{P}<0,05)$ pelos programas de iluminação (Tabela 1). Maior massa foi registrada nos ovos das aves do programa com luz natural. Os ovos obtidos nos programas contínuo e intermitente apresentaram massa semelhante. Estes resultados podem ser justificados pela maior porcentagem de postura registrada no programa luz natural, já que o peso dos ovos foi semelhante nos programas estudados e estas variáveis são usadas para o cálculo da massa.

Rowland (1987), após estudar o comportamento das aves sob diferentes programas de iluminação, afirmou que a massa de ovos varia conforme o modelo de iluminação usado. Daí, pode-se concluir que o uso do programa intermitente testado no presente estudo não resulta em maior massa de ovos.

A conversão alimentar (g/g) por massa de ovos das poedeiras leves (Tabela 1$)$ variou $(\mathrm{P}<0,05)$ conforme o programa de iluminação fornecido.

As aves do programa luz natural converteram melhor o alimento quando comparadas com as dos outros programas. A conversão das aves no programa intermitente foi melhor que a no contínuo. 
TABELA 1 - Consumo de ração (CR), produção de ovos (PR), peso de ovos (PO), massa de ovos (MO) e conversão alimentar (CA) segundo o programa de iluminação*.

\begin{tabular}{lccccc}
\hline $\begin{array}{c}\text { Programa de } \\
\text { Iluminação }\end{array}$ & $\begin{array}{c}\text { CR } \\
\text { (g/ave/dia) }\end{array}$ & $\begin{array}{c}\text { PR } \\
\mathbf{( \% )}\end{array}$ & $\begin{array}{c}\text { PO } \\
\text { (g) }\end{array}$ & $\begin{array}{c}\text { MO } \\
\text { (g) }\end{array}$ & $\begin{array}{c}\text { CA } \\
\text { (g/g) }\end{array}$ \\
\hline Contínuo & $99,78 \mathrm{~A}$ & $63,05 \mathrm{~B}$ & $71,80 \mathrm{~A}$ & $45,16 \mathrm{~B}$ & $2,53 \mathrm{C}$ \\
Intermitente & $98,22 \mathrm{~B}$ & $62,64 \mathrm{~B}$ & $72,38 \mathrm{~A}$ & $45,25 \mathrm{~B}$ & $2,25 \mathrm{~B}$ \\
Luz Natural & $97,84 \mathrm{~B}$ & $67,90 \mathrm{~A}$ & $71,57 \mathrm{~A}$ & $48,51 \mathrm{~A}$ & $2,06 \mathrm{~A}$ \\
\hline
\end{tabular}

* Médias seguidas de letras distintas na coluna diferem significativamente $(\mathrm{P}<0,05)$.

A conversão alimentar por massa de ovos é a relação entre o consumo de ração e a massa de ovos. $\mathrm{O}$ resultado obtido pode ser justificado pela maior massa de ovos verificada nas aves do programa luz natural e pelo seu menor consumo de ração. Resultados semelhantes foram observados por Ernst et al. (1987) em revisão sobre programas de iluminação. Os mesmos autores no entanto, não recomendam o uso destes programas antes das 36 semanas de idade porque resultarão em redução na produção de ovos.

Por outro lado, Koelkebeck (1986), trabalhando com poedeiras Leghorn brancas, concluiu que, apesar das aves submetidas ao programa intermitente terem consumido menor quantidade de ração, a conversão alimentar não apresentou diferença nos programas testados.

\section{CONCLUSÃO}

O fornecimento de programas de iluminação intermitente e de apenas iluminação natural, em dias de luminosidade crescente, permitem manter o bom desempenho zootécnico de poedeiras leves, ao final de produção.

\section{REFERÊNCIAS BIBLIOGRÁFICAS}

CENTRAIS ELÉTRICAS DE MINAS GERAIS. Cemig. Disponível em: <http://www.cemig.com.br>. Acesso em: 10 set. 2001.

CHARLES, D. R.; TUCKER, S. A. Response of modern hybrid laying strocks to change in photoperiod. British Poultry Science, London, v. 34, p. 241-254, 1993.

COTTA, J. T. B. Galinha: produção de ovos. Viçosa: Aprenda Fácil, 2002. 260 p.

ERNST, R. A.; MILLAM, J. R.; MATTHER, F. B. Review of life-history lighting program for commercial laying fowls. World's Poultry Science Journal, Ithaca, v. 43, n. 1, p. 44-55, Feb. 1984.
ETCHES, R. J. Reproducción aviar. Zaragoza: Acribia, 1996. $339 \mathrm{p}$.

FERREIRA, D. F. Sistema de análise estatística para dados balanceados - SISVAR. Lavras: UFLA/DEX, 2000.

KOELKEBECK, K. W. Hemeral light-dark and intermittent photoperiod effects on laying hens. Poultry Science, Champaign, v. 65, n. 11, p. 2002-2007, 1986.

LEWIS, P. D.; PERRY, G. C. Response of laying hens to assimetrical interrupted lighting regimens: physiological aspects. British Poultry Science, London, v. 31, p. 45-52, 1990.

MIDGLEY, M.; MORRIS, T. R.; BUTLER, E. A. Experiment with the biomittent light system for laying hens. British Poultry Science, London, v. 29, n. 2, p. 333-342, 1988.

MORRIS, T. R. Use of intermitent light to save feed and to improve egg shell quality in laying flocks. In: WORLD'S POULTRY CONGRESS, 17., 1988, Nagoya. Proceedings... Nagoya: Jp. Poultry Association, 1988. p. 161-164.

MORRIS, T. R.; MIDGLEY, M. M.; BUTLER, E. A. Effect of age at starting Biomittent light on performance of laying hens. British Poultry Science, London, v. 31, p. 447-455, 1990.

NYS, Y.; MONGIN, P. The effect of 6 and 8 hour light/dark cycles on egg production on pattern of oviposition. British Poultry Science, London, v. 22, p. 391-397, 1981.

ROWLAND, K. W. Intermitent lighting for laying fowls: a review. World's Poultry Science Journal, Ithaca, v. 41, n. 1, p. 5-20, 1987. 
SAUVEUR, B. Photopériodisme et reproduction des oiseaux domestiques femelles. Animal Production, Edinburgh, v. 9, n. 1, p. 25-34, 1996.
SAUVEUR, B.; MONGIN, P. Performance of laying reared and/or kept under different 6-hour light/dark cycles. British Poultry Science, London, v. 24, n. 2, p. 405-416, 1983. 